\title{
CONTENTS OF VOLUME 14
}

Preface.......................... VII

Contents of Volumes $1-13$, Including Bibliographical Information. . . . . IX

Contents of Volumes 1 13, Alphabetized by Authors' Names . . . . . . . XIX

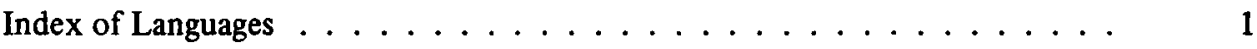

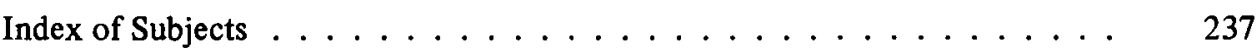

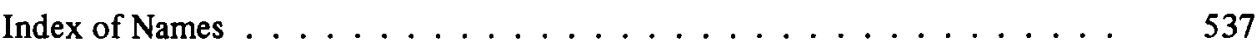

Biographical Notes of Editors and Contributors . . . . . . . . . 865 
